\title{
Specialist mental health services in England in 2014: overview of funding, access and levels of care
}

\author{
Mary Docherty ${ }^{1,2}$ and Graham Thornicroft ${ }^{3^{*}}$
}

\begin{abstract}
Background: Since the economic recession began in 2008 anecdotal reports suggest that mental health services in England have experienced disinvestment, but published data to test this proposition are few.

Method: This paper presents information from a wider range of official, research and grey literature sources aiming to: (1) assess whether governmental investment in publically funded mental health services has declined since the start of the economic recession in 2008; (2) to assess whether relative changes in mental health service investment over this period were or were not similar to trends in national investment in services for people with physical disorders, and (3) to interpret these findings in terms of met and unmet population levels needs for mental health care.

Results: The key findings are that: across England social service expenditure reductions have led to a decrease of $48 \%$ in the number of people with mental illness who receive such care, while direct NHS expenditure was reduced in some local areas by up to $32 \%$.

Conclusions: The results of this overview suggest that there have been substantial reductions in the resources dedicated to mental health treatment and care in England since 2008, that such reductions seem not to have been applied to physical health services, and that these findings appear to run counter to the government policy of'parity of esteem; for mental and physical healthcare.
\end{abstract}

Keywords: Mental health services, Mental health systems, Healthcare resources, Finances, Investment, Access, Coverage, Levels of care

\section{Background}

This year sees the publication of the Chief Medical Officer's (CMO) Annual Public Health Report for England-the topic for 2014 was Public Mental Health. This brings together the best evidence in the field, set within a contemporary policy context, and informs the CMO's recommendations for the further development of mental health in England. Although one in four adults experience at least one diagnosable mental health problem in any year, there is emerging evidence that most people

\footnotetext{
*Correspondence: graham.thornicroft@kcl.ac.uk

${ }^{3}$ Health Service and Population Research Department, Institute of Psychiatry, Psychology and Neuroscience, King's College London, De Crespigny Park, London SE5 8AF, UK
}

Full list of author information is available at the end of the article with mental disorders in England receive no relevant healthcare [1].

As part of the CMO Report, we were commissioned to write an overview of gaps in mental health service provision in England. The aim of this paper is to summarise these gaps in terms of funding, access, treatment and care. We draw upon all the available data on resources (and disinvestment) in mental health services in England in recent years, in relation to population levels of need. We go on to consider whether recent cuts in NHS mental health services are comparable the resource levels available in acute/physical care, given the recent governmental legal commitment to 'parity of esteem'.

Mental health services in England have been historically characterised by significant variations in service provision, quality of care, and acceptability to users 
[2]. The National Service Framework for Mental Health (NSFMH) for England imposed a standard models of care, and was substantially implemented through a financial incentives system, and led to improvements in the availability and quality of provision in mental health services in England [3]. In 2011 the Coalition Government's mental health strategy for England (entitled 'No Health without Mental Health') [4] recognised the need for ongoing improvements in quality and provision. It set six key targets including improvements in safety, patient-centeredness, recovery and physical health. Yet this emerged at the same time as considerable structural change in the NHS, related to the "Nicholson Challenge' to hold overall expenditure steady, and with substantial restructuring for commissioners and providers in the NHS, governed by the 2012 Health and Social Care Act.

In terms of the national mental health service context, about a quarter of people with depression and anxiety in England receive treatment, most often in primary care settings $[5,6]$, while the large major of specialist mental health care is provided by National Health Service (NHS) staff. At the same time there has been a trend over the last decade for governments to stimulate a 'mixed economy' of NHS, for-profit and non-for-profit service providers. Until 1999 the pattern of mental health services was largely determined by local planners. A national 10 year plan for England was introduced in 1999 that set a clear profile of community mental health services to be provided in each local district [7]. Since 2010 a greater degree of 'localism' has been encouraged by the subsequent national mental health plan, in which local service commissioners can purchase services on the basis of a local assessment of needs, and not on the basis of a nationally specified pattern of care [4]. Some of the most important system wide key performance indicators, such as a maximum waiting time of 18 weeks to be seen by a specialist after a referral from primary care, especially excluded mental health care from this requirement, until a policy change in 2015 .

Mental health services have long been considered to be the poor relation to physical/acute care, often described as being subject to less investment or greater disinvestment in times of plenty or scarcity [8]. Yet to date hard data on this alleged disparity have been difficult to identify. Conflicting Governmental guidance has emerged. The Department of Health's 2014 policy guide on according equal value to mental and physical health (so-called 'Parity of Esteem') [9] is an important step forward in principle. Conversely, the imposition of a 'tariff deflator' (i.e. resource reduction), a fifth higher for mental health than for acute healthcare appears to undermine the overall policy intention [10].

\section{Method}

In this context the method used in conducting this overview paper was to identify all available sources of information on governmental mental health investment (both health and social services) in England over the last decade. The sources used were: government Budgetary Programme Data, online searches of MedLine, PubMed, Ovid, Department of Health policy documents, Freedom of Information request reports, charitable and other grey literature reports, data from experts in the field (using a snowballing technique to identify all possible sources of relevant material), and other material from internet search engines. We also received detailed time trend budget data from one mental health provider trust in England.

\section{Results and discussion}

Increasing demand for mental health services during the economic recession

On the demand side, the prevalence of mental illness has been observed to increase during times of economic recession, while there is some evidence for increased suicidality during the period of economic austerity since 2008 [11, 12]. In terms of patterns of supply, one part of the picture is investment in social care support. Since 2005, 30,000 people with mental health problems have lost their social care support, following a $£ 260 \mathrm{~m}$ (standardised figures) shortfall in funding due to cuts to local authority budgets, greater than for any other client group-a relative fall of $48 \%$ of clients receiving social care [13] (see Figs. 1, 2).

\section{The 'treatment gap' in mental health service provision}

Mental illnesses are the largest source of disability in the England. The Centre for Mental Health estimates that the aggregated economic and social costs of mental illness in England in 2009-2010 was $£ 105.2$ bn. This includes $£ 21.3 \mathrm{bn}$ in health and social care costs, $£ 30.3 \mathrm{bn}$ in lost economic output, and $£ 53.6$ bn in disability [14]. It is striking that in relation to the $28 \%$ of total burden of disease which is attributable to mental illness in England, mental health care receives $13 \%$ of total NHS spending [15]. There is an 'inverse care law' in that about $3 / 4$ of people with long term physical disorders received treatment in England over the same time period, compared with about $1 / 4$ of people with long term mental disorders. Indeed this is a global phenomenon-proportionately more people with physical disorders are treated in the poorest countries of the world, than are treated for mental disorders in high income countries such as England [1] (see Table 1).

There is evidence that this 'treatment gap' is pervasive across all mental health disorders and all age groups 


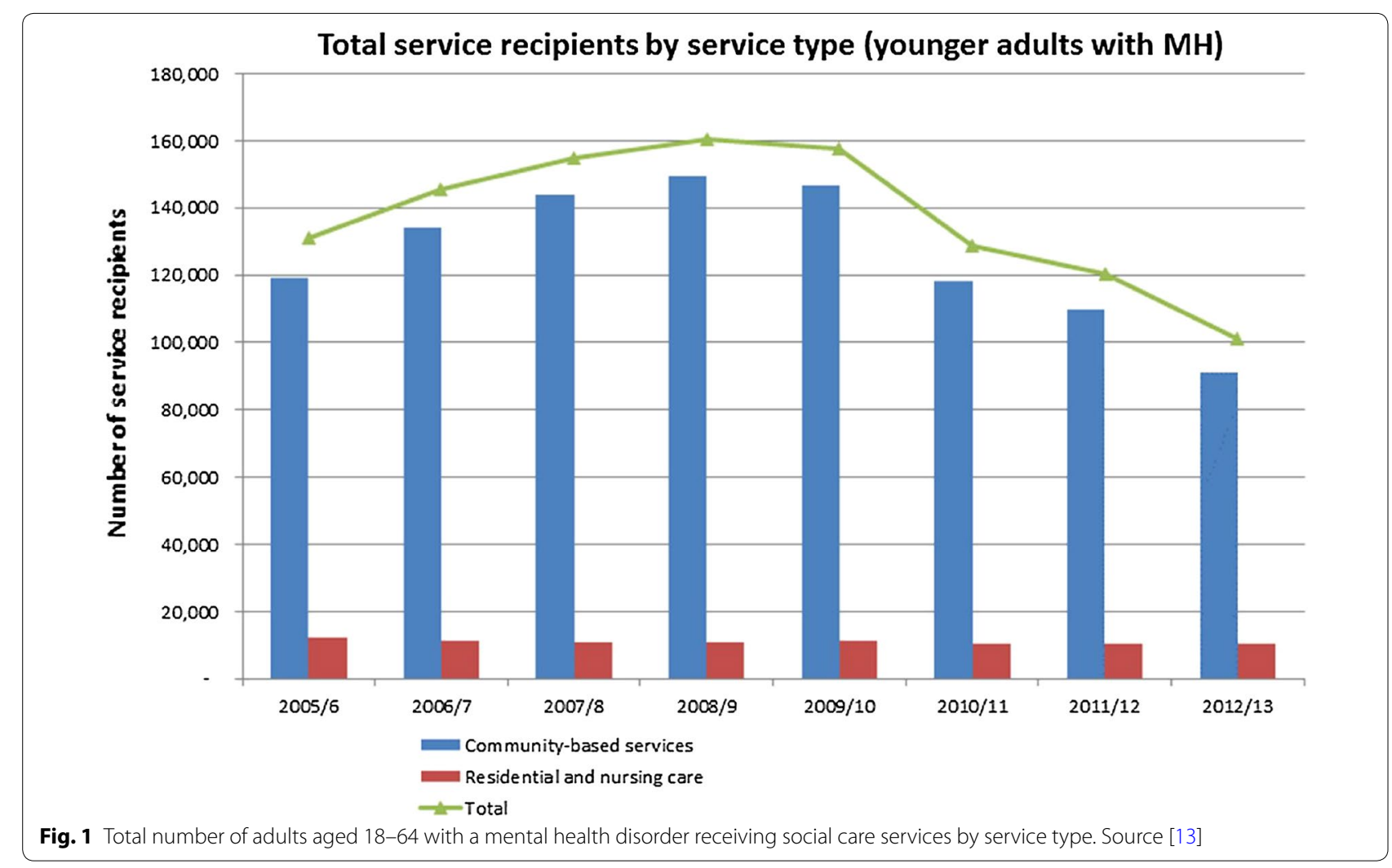

Fig. 1 Total number of adults aged 18-64 with a mental health disorder receiving social care services by service type. Source [13]

\begin{tabular}{|c|c|c|c|c|c|c|c|c|}
\hline observe & & 180 & 200 & 190 & 121 & 121 & 120 & 1090 \\
\hline rdised & 1,180 & 1,160 & 1,150 & 1,130 & 1,140 & 1,090 & 960 & 920 \\
\hline
\end{tabular}

Fig. 2 Observed and standardised net current expenditure by year (£millions). Source [13]

Table 1 Treatment gap: treated prevalence for mental disorders in high, medium and low income settings

\begin{tabular}{llc}
\hline & High income countries (\%) & $\begin{array}{c}\text { Low and middle income } \\
\text { countries }\end{array}$ \\
\hline Physical disorders & & 77 \\
$\quad$ Diabetes & 94 & 51 \\
Heart disease & 78 & 44 \\
Asthma & 65 & 8 \\
Mental disorders & 29 & 13 \\
Depression & 29 & 9 \\
Bipolar disorder & 33 & \\
Panic disorder & & \\
\hline
\end{tabular}

Source: data from the 2002-2004 WHO World Mental Health Survey [1]

(Box 1). In England, the most recent national psychiatric morbidity surveys for children and adolescents (2004) and adults (2007) show that the large majority of people with all mental disorders (except psychosis) receive no treatment $[16,17]$. For example, a total of about 4.5 million adults and 525,000 children with anxiety/depression 
will not receive treatment $[15,16]$ this year. It is clear that very substantial change is required to achieve 'parity of esteem?

\section{Box 1 Examples of gaps in treatment in UK provision} of mental health services

Among people with severe mental illness, $29 \%$ have received appropriate physical health checks in the past year [16]

$20 \%$ of adults who screened positive for Attention Deficit Hyperactiv-

ity Disorder were receiving medication, counselling or therapy for a mental health or emotional problem [16]

$14 \%$ of alcohol dependent adults were receiving treatment for a mental or emotional problem [16]

Despite higher prevalence, older people are less likely than working age adults to be diagnosed with depression by their GP, and IAPT services are not yet configured to meet their needs, with IAPT access rates of just $5.2 \%[16]$

Only $28 \%$ of parents of children with a conduct disorder have sought advice from a mental health specialist [17]

People with long-term conditions are 2-3 times more likely to experience mental illness than the general population, yet in $2 / 3$ of cases depression goes undetected and untreated

\section{Disinvestment and the treatment gap}

These levels of treatment coverage (i.e. the proportion of all people with a condition who actually receive treatment) is largely related to investment in services (although some demand side factors, especially stigma, can play a major role [18]. There are now concerns that overall expenditure reductions will fail to meet the increasing demand and may compromise patient safety and service quality. Nevertheless, the primary source of data to examine such claims was recently decommissioned for funding by Government, so that such data are not available after 2012. Current information, including Programme Budgeting Data, do not provide sufficient detail to identify levels of need, or variations in service provision.

There is evidence that there have been reductions in investment in community mental health services in recent years (see Figs. 3, 4). The 2011/12 survey, for example, found that investment in mental health services for adults of working age (aged 18-64), to a total of $£ 6.629$ billion, fell in real terms from the previous year. This was the first real terms drop in investment since the survey began in 2001/02 [19]. Between 2010/11 and 2011/12 investment across the three priority areas in community mental health services (crisis resolution, early intervention and assertive outreach) fell, for the first time in a decade, by $£ 29.3$ million from $£ 520$ million to $£ 490.7$ million. This is significant given the evidence base for these services in reducing admissions to hospital and the continuing demand for acute beds [20]. Funding for older people's mental health services was found to be under greater pressure, with a $1 \%$ fall in resource allocation in the previous year to $£ 2.830$ billion in $2011 / 12$. After allowing for inflation of service costs, this amounts to a real terms cut of 3.1 per cent. There is also evidence to suggest significant regional variations, for example service reductions being greater in London than in other parts of England [21].

There are no comparable official data for child and adolescent mental health services (CAMHS). We therefore gathered data by other means, including surveys by the third sector (i.e. both for profit and not for profit provider organisations) and Freedom of Information (FOI) requests. One survey found that 67 per cent of councils had reduced CAMHS funding between 2010 and 2013

\begin{tabular}{cccccc}
\multicolumn{7}{c}{ Real Term Investment in f'Billions } \\
Estimated \\
Year & $\begin{array}{c}\text { Reported } \\
\text { Investment }\end{array}$ & $\begin{array}{c}\text { Unreported } \\
\text { Investment }\end{array}$ & $\begin{array}{c}\text { Total } \\
\text { Investment }\end{array}$ & $\begin{array}{c}\text { Annual } \\
\text { Increase }\end{array}$ & \% Increase \\
\hline $2001 / 02$ & 4.002 & 0.160 & 4.162 & & \\
$2002 / 03$ & 4.348 & 0.274 & 4.622 & 0.460 & $11.1 \%$ \\
$2003 / 04$ & 4.773 & 0.040 & 4.814 & 0.191 & $4.1 \%$ \\
$2004 / 05$ & 5.309 & 0.055 & 5.364 & 0.550 & $11.4 \%$ \\
$2005 / 06$ & 5.442 & 0.262 & 5.703 & 0.339 & $6.3 \%$ \\
$2006 / 07$ & 5.618 & 0.194 & 5.812 & 0.108 & $1.9 \%$ \\
$2007 / 08$ & 6.066 & 0.019 & 6.085 & 0.274 & $4.7 \%$ \\
$2008 / 09$ & 6.249 & 0.046 & 6.295 & 0.210 & $3.4 \%$ \\
$2009 / 10$ & 6.298 & 0.338 & 6.636 & 0.341 & $5.4 \%$ \\
$2010 / 11$ & 5.780 & 0.914 & 6.694 & 0.058 & $0.9 \%$ \\
$2011 / 12$ & 5.717 & 0.912 & 6.629 & -0.066[ & $-1.0 \%$ \\
\hline Increase in the 10 years 2001/02 to 2011/12 & $\mathbf{2 . 4 6 7}$ & & $59.3 \%$
\end{tabular}

Fig. 3 Total real investment in adult mental health services 2001/02 to 2011/12 (at 2011/12 pay and price levels). Source [34] 


\section{Real Term Investment at 2011/12 levels}

\begin{tabular}{|c|c|c|c|c|c|c|}
\hline & $\begin{array}{l}\text { Assertive } \\
\text { Outreach }\end{array}$ & $\begin{array}{l}\text { Crisis Resolution / } \\
\text { Home Treatment }\end{array}$ & $\begin{array}{c}\text { Early } \\
\text { Intervention in } \\
\text { Psychosis }\end{array}$ & $\begin{array}{c}\text { Total in } \mathbf{f} \\
\text { millions }\end{array}$ & $\begin{array}{l}\text { \% real } \\
\text { increase } \\
\text { per year }\end{array}$ & $\begin{array}{l}\text { Actual } \\
\text { Increase }\end{array}$ \\
\hline $2002 / 03$ & 77.5 & 38.2 & 8.0 & 123.6 & & \\
\hline $2003 / 04$ & 95.5 & 73.2 & 15.7 & 184.4 & $49 \%$ & 60.8 \\
\hline $2004 / 05$ & 112.9 & 130.3 & 28.1 & 271.3 & $47 \%$ & 86.9 \\
\hline $2005 / 06$ & 118.0 & 180.5 & 48.7 & 347.2 & $28 \%$ & 75.9 \\
\hline $2006 / 07$ & 122.2 & 206.5 & 57.4 & 386.1 & $11 \%$ & 38.9 \\
\hline $2007 / 08$ & 137.5 & 235.2 & 76.1 & 448.8 & $16 \%$ & 62.8 \\
\hline $2008 / 09$ & 140.8 & 254.8 & 99.5 & 495.2 & $10 \%$ & 46.3 \\
\hline $2009 / 10$ & 141.1 & 259.9 & 107.3 & 518.4 & $5 \%$ & 23.2 \\
\hline $2010 / 11$ & 138.6 & 266.1 & 104.1 & 520.0 & $0 \%$ & 1.6 \\
\hline $2011 / 12$ & 126.8 & 254.6 & 109.3 & 490.7 & $-6 \%$ & -29.3 \\
\hline \multicolumn{4}{|c|}{$\begin{array}{l}\text { Real term increase } 2002 / 03 \text { to } 2011 / 12 \text { in } £^{\prime} \text { millions } \\
\text { Real term investment in priority service areas } 2002 / 3 \text { to } 2011 / 2 \text {. Source [34] }\end{array}$} & 367.1 & & \\
\hline
\end{tabular}

[22]. Regional cuts in spending were as high as $12 \%$ in the North East and $13 \%$ in the East of England [22] over this period.

The $\mathrm{BBC}$ and the Community Care journal published figures in 2013, based upon a FOI request, with responses from 43 of 51 mental health trusts $n$ England. Comparing 2011/12 budgets with those for $2013 / 14$, they found a real terms reduction of $2.36 \%$, while funding for psychological therapies increased by $6 \%$ in real terms (source: http://www.bbc.com/news/ health-24537304.)

Despite official figures estimating 1-2 \% real terms decreases in expenditure, case study information from individual Trusts published in the Chief Medical Officer's 2014 Report suggests that these figures may fall far short of actual disinvestment. One large metropolitan mental health trust reported that over the period from $2009 / 10$ to $2013 / 14$ it had seen a net reduction in funding of $£ 12 \mathrm{~m}$, 'with the pace of net disinvestment being accelerated and set to do so further'. They report that 'If the funding provided by the Department of Health and which passes through Clinical Commissioning Groups (CCGs) then the net gain to local CCGs from disinvestment and efficiency in local mental health services has been approximately $£ 50 \mathrm{~m}$. In each of our local CCGs we have seen net savings from mental health services of at least $32 \%$ over the last 7 years. These are far in excess of official estimates, and support a series of concerns summarised in Box 2.
Box 2 Key messages on the treatment gap in mental health services in England

There is a very significant overall treatment gap in mental health with about $75 \%$ of people with mental illness receiving no treatment at all [1]

The treatment gap contributes to unacceptably high mortality rates, as the available data suggest that people with mental illness can die up to 15-20 years earlier on average than individuals without mental illness $[35,36]$

There are significant and inappropriate variations in the delivery of mental health services [9]

Information on mental health service expenditure currently lack sufficient detail

There is a clear fall in investment and expenditure despite evidence of an increase in mental health burden $[12,17,21]$

It is unclear whether the disinvestment has been greater for mental than for physical health provision

There appear to be considerable discrepancies between overall nationa figures for resource reductions and the figures available locally from mental health Trusts

There are no available data sets which capture the implications for mental health services of aggregate expenditure reductions across multiple sectors (criminal justice, social care, non-statutory, and the voluntary sectors)

\section{Service accessibility and waiting times}

Mental health services are currently exempt from the 18 week maximum waiting time for service access stipulated in the NHS Constitution. Service user data indicates that over $12 \%$ of people wait longer than 1 year to start treatment, whilst $54 \%$ wait over 3 months [23]. The number of people presenting in a mental health crisis have increased in recent years [24], and $40 \%$ of mental health trusts have staffing levels below established benchmarks 
for crisis services (http://www.mind.org.ug/crisiscare). Waiting times for emergency assessment, for example in police cells or Mental Health Act Section 136 Suites, have escalated in recent years, along with increasing use of the police and criminal justice system to 'care' for individuals when unwell due to insufficient capacity in mental health services [25]. Nevertheless the quality of data about these acute issues is poor. The Care Quality Commission, for example, has raised concerns about bed occupancy rates for many years [26] yet their most recent report does not report on bed occupancy rates (see: http:// www.england.nhs.uk/statistics/statistical-work-areas/ bed-availability-and-occupancy/bed-data-overnight/).

Limitations in data sources have led to increased freedom of information requests and professional surveys to investigate these concerns (Box 3). These findings include a reported $9 \%$ reduction in mental health beds between 2011 and 2012 and a doubling of patients being sent out of area for treatment between 2011/12 and 2013/4 [27] (see: http://www.communitycare.co.uk/2013/10/16/ patients-at-risk-as-unsafe-mental-health-services-reachcrisis-point-2/\#.U3WoVq1dUv0)

\section{Box 3 Summary of recent freedom of information requests and survey findings}

A minimum of 1711 mental health beds have been closed since April 2011, including 277 between April and August 2013. This is a $9 \%$ reduction in the total number of mental health beds - 18,924-available in 2011/12

http://www.communitycare.co.uk/2013/10/16/patients-at-risk-asunsafe-mental-health-services-reach-crisis-point-2/\#.U3WoVq1dUv0

A 2013 survey of members of the Child and Adolescent Psychiatry Faculty was carried out $77 \%$ of respondents to a 2013 survey of members of the Child and Adolescent Psychiatry Faculty about their experience of admitting young people to inpatient unit reported difficulties in accessing admissions to inpatient beds. $79.1 \%$ respondents reported safeguarding concerns/incidents whilst waiting for a bed; $76.5 \%$ reported young people with unacceptably high risk profiles being managed in the community due to lack of beds; $61.9 \%$ reported young people being held in inappropriate settings [37]

Freedom of information data from 30 trusts, reported the number of patients sent out of area has more than doubled between 2011/2 and 2013/14 (1301 in 2011/12 to 3024 in 2012/3). The costs associated with this reported by 23 Trusts show an increase in expenditure from $£ 21.1 \mathrm{~m}$ in $2011 / 12$ to $£ 38.3 \mathrm{~m}$ in $2012 / 13$ http://www.bbc.co.uk/news/uk-27285555

\section{Admission, compulsion and suicides}

The number of psychiatric hospital admissions is now about double that figure for 2000 [19]. Use of the Mental Health Act has also steadily grown in recent years, and in $2012 / 13$ there was a 4 per cent increase in compulsory detentions in comparison to the previous year [28]. The Care Quality Commission and service user experience surveys show ongoing poor involvement of service users in their care [29]. The Care Quality Commission reports ongoing inappropriate restrictive practices and cultures in many wards demonstrating a 'significant gap between practice and the ambitions of the national mental health policy [30].

\section{Discussion}

Disregard for the needs of people with mental illness has been described by some authors as 'structural discrimination' [31, 32]. This concept can also be applied to lack of investment in information infrastructure to be able to know whether services are improving or not.

There are several important limitations of this study. The research deliberately sought all relevant sources of information about the levels of investment in mental health care in England, and recent trends, and this meant that these sources were very heterogeneous and drew upon a wide variety of official data, research reports, the grey literature and case studies. We therefore would not place very heavy weight upon individual sources, but rather wish to interpret the overall pattern of results. Second, the time frame used for the data sources varied somewhat, with some referring to the period since 2008 when the economic recession began, and other to the period of the government at the time, which came into power in 2010. Further, we have brought together information across a wide range of sources, but it is true that there are few sources of information about true prevalence and treated prevalence across all diagnostic groups, and such data are not routinely and repeatedly collected and reported by the government. It also needs to be kept in mind that rates of service utilization (and deductions about rates of unmet need) may differ when reported by service users or by service providers [33, 34]. In addition, it is possible that there were types of substitution (for example with fewer community services in recent years has this been associated with a greater demand for psychiatric beds?), but we were not able to identify data to bear upon this issue.

The recent governmental commitment to 'parity of esteem' [9] is long overdue. Yet the policy requirements which have been applied to acute/physical healthcare, such as the 18 week waiting time limit, have still not been applied equally to mental health care. It is also clear that unintended consequences of the tariff system (cut more in recent years for mental than for mental health care) have systematically disadvantaged both commissioners and providers of mental health care. Poorly integrated financial monitoring processes have contributed to a failure to alert all parts of the NHS to how far resource reductions have harmed the quantity and quality of mental health care in recent years. In the post 2013 structure of the NHS separate health, social care and public health outcomes frameworks are making it even harder 
to commission joint or integrated services, to avoid gaps in provision, and to monitor progress or deterioration in services. At the same time it needs to be acknowledged that within this context of overall disinvestment in mental health care, some services are being expanded, particularly the remit of the Improving Access to Psychological Therapies (IAPT) services. Taken as a whole, these findings are far from reassuring for everyone dedicated to better mental health care in England.

\section{Authors' contributions}

MD is an Academic Clinical Fellow at King's College London, Institute of Psychiatry, Psychology and Neuroscience, and is a Specialty Registrar at the South London and Maudsley NHS Foundation Trust. She was formerly a Medical Advisor to the Director of Research and Development at the National Institute for Clinical and Health Excellence. She undertook the primary data retrieval, and wrote the first draft of this paper. GT is Professor of Community Psychiatry at King's College London, Institute of Psychiatry, Psychology and Neuroscience, and is Consultant Psychiatrist at the South London and Maudsley NHS Foundation Trust. He has published extensively on mental health services, and their evaluation, on stigma and discrimination, and on global mental health. He supervised the design, conduct and writing up of this paper, which is based upon a chapter on Service Gaps in the UK Chief Medical Officer' 2014 Annual Public Health Report on Public Mental Health. GT is the guarantor of the paper. Both authors read and approved the final manuscript.

\section{Author details}

${ }^{1}$ Institute of Psychiatry, Psychology and Neuroscience, King's College London, London, UK. ${ }^{2}$ South London and Maudsley NHS Foundation Trust, London, UK. ${ }^{3}$ Health Service and Population Research Department, Institute of Psychiatry, Psychology and Neuroscience, King's College London, De Crespigny Park, London SE5 8AF, UK.

\section{Acknowledgements}

The authors are pleased to acknowledge the important contributions of the following organisations and individuals to this paper: Centre for Mental Health, MIND, Rethink Mental IIIness, Royal College of Psychiatrists, and other members of the Mental Health Policy Group, Martin Baggaley, Andy Bell, Gyles Glover, Gus Heafield, Martin Knapp, David McDaid, Nisha Mehta, and Helen Undy. GT is supported by the NIHR CLAHRC South London and the NIHR BRC at the South London and Maudsley NHS Foundation Trust. MD is an NIHR Academic Clinical Fellow.

\section{Compliance with ethical guidelines}

\section{Competing interests}

Both authors declare that they have no competing interests.

Received: 28 March 2015 Accepted: 11 August 2015

Published online: 30 August 2015

\section{References}

1. Ormel J, Petukhova M, Chatterii S, Guilar-Gaxiola S, Alonso J, Angermeyer MC, et al. Disability and treatment of specific mental and physical disorders across the world. Brc J Psychiatry. 2008;192:368-75.

2. Saxena S, Thornicroft G, Knapp M, Whiteford $H$. Resources for mental health: scarcity, inequity, and inefficiency. Lancet. 2007;370(9590):878-89.

3. McCrone P, Dhanasiri S, Patel A, Knapp M, Lawton-Smith S. Paying the price. The cost of mental health care in England to 2026. London: King's Fund; 2008

4. Department of Health. No health without mental health: a cross-government mental health outcomes strategy for people of all ages. London: Department of Health; 2011.
5. Meltzer $H$, Bebbington $P$, Brusha T, Farrell, Jenkins R, Lewis $G$. The reluctance to seek treatment for nuerotic disorders. J Mental Health. 2000;9(3):319-27.

6. Singleton N, Meltzer $\mathrm{H}$, Jenkins R. Building a picture of psychiatric morbidity in a nation: a decade of epidemiological surveys in Great Britain. Int Rev Psychiatry. 2003;15(1-2):19-28.

7. Department of Health. National Service Framework for Mental Health. Modern Standards and Service Models. London: Department of Health; 1999.

8. Goldberg D. Improved investment in mental health services: value for money? [Review] [13 refs]. Br J Psychiatry. 2008;192(2):88-91.

9. Social Care Local Government and Care Partnership Directorate. Closing the gap: priorities for essential change in mental health. London: Department of Health; 2014

10. NHS England/Commissioning Policy and Primary Care/Commissioning Policy \& Resources. Commissioning for Quality and Innovation (CQUIN): 2014/15 guidance. London: NHS England; 2013.

11. Evans-Lacko S, Knapp M, McCrone P, Thornicroft G, Mojtabai R. The mental health consequences of the recession: economic hardship and employment of people with mental health problems in 27 European countries. PLoS One. 2013;8(7):e69792. doi:10.1371/journal.pone.0069792.

12. Katikireddi SV, Niedzwiedz CL, Popham F. Trends in population mental health before and after the 2008 recession: a repeat cross-sectional analysis of the 1991-2010 Health Surveys of England. BMJ Open. 2012;2(5). doi:10.1136/bmjopen-2012-001790.

13. Fernandez J-L, Snell T, Wistow G. Changes in the patterns of social care provision in England: 2005/6 to 2012/13. Canterbury: Personal Socia Services Research Unit, University of Kent; 2013.

14. Center for Mental Health. The economic and social costs of mental health problems in 2009/10. London: Centre for Mental Health; 2010

15. Centre for Economic Performance's Mental Health Policy Group. How mental illness loses out in the NHS. London: Centre for Economic Performance, London School of Economics and Political Science; 2012.

16. McManus S, Meltzer H, Brugha T, Bebbington P, Jenkins R. Adult psychiatric morbidity in England, 2007-Results of a household survey. Leeds: The NHS Information Centre for health and social care; 2009.

17. Green H, McGinnity A, Meltzer H, Ford T, Goodman R. Mental health of children and young people in Great Britain 2004. London: Palgrave McMillan; 2005

18. Clement S, Schauman O, Graham T, Maggioni F, Evans-Lacko S, Bezborodovs $\mathrm{N}$ et al. What is the impact of mental health-related stigma on help-seeking A systematic review of quantitative and qualitative studies. Psychol Med. 2014, pp 1-17. doi:10.1017/S0033291714000129.

19. Mental Health Network: NHS Confederation. Key facts and trends in mental health. London: NHS Confederation; 2014.

20. Glover G, Arts G, Babu KS. Crisis resolution/home treatment teams and psychiatric admission rates in England. Br J Psychiatry. 2006;189(5):441-5.

21. Clover B. Mental health falling behind: London sector taking disproportionate share of cuts, leak shows. Health Serv J. 2011;13.

22. Young Minds. Children missing out as local authorities scale back mental health. London: MIND; 2013

23. Mind. We still need to talk. London: MIND; 2013.

24. British Medical Association. Recognising the importance of physical health in mental health and intellectual disability-achieving parity of outcomes. London: British Medical Association; 2014

25. Her Majesty's Inspectorate of Constabulary HMsloP, the Care Quality Commission and Healthcare Inspectorate Wales. A Criminal use of police cells?. London: Her Majesty's Inspectorate of Constabulary; 2013.

26. House of Commons Health Committee. First report post-legislative scrutiny of the mental Health Act 2007, HC 584. London: House of Commons; 2013

27. Care Quality Commission. Monitoring the mental health act in 2012/13. London: Care Quality Commission; 2014.

28. Health and Social Care Information Centre. Annual Report England 2013. Inpatients formally detained in hospitals under the Mental Health Act 1983, and patients subject to supervised community treatment. London: Health and Social Care Information Centre; 2013.

29. Care Quality Commission. Community mental health survey 2013. London: Care Quality Commission; 2013

30. Care Quality Commission. Monitoring the Mental Health Act in 2011/12 London: Care Quality Commission; 2013. 
31. Corrigan PW, Markowitz FE, Watson AC. Structural levels of mental illness stigma and discrimination. Schizophr Bull. 2004;30(3):481-91.

32. Thornicroft G. Shunned: discrimination against people with mental illness. Oxford: Oxford University Press; 2006

33. Kisely S, Lin E, Lesage A, Gilbert C, Smith M, Campbell LA, et al. Use of administrative data for the surveillance of mental disorders in 5 provinces. Can J Psychiatry. 2009;54(8):571-5.

34. Mental Health Strategies. $2011 / 12$ National Survey of investment in adult mental health services. London: Department of Health; 2012.

35. Thornicroft $G$. Physical health disparities and mental illness: the scandal of premature mortality. Br J Psychiatry. 2011;199(6):441-2. doi:10.1192/bjp. bp.111.092718.
36. Lawrence D, Hancock KJ, Kisely S. The gap in life expectancy from preventable physical illness in psychiatric patients in Western Australia: retrospective analysis of population based registers. BMJ. 2013;346:f2539. doi:10.1136/bmj.f2539.

37. Hindley P. Written evidence to the House of Commons Select Committee Inquiry in Child and Adolescent Mental Health Services. London: House of Commons; 2014.

\section{Submit your next manuscript to BioMed Central} and take full advantage of:

- Convenient online submission

- Thorough peer review

- No space constraints or color figure charges

- Immediate publication on acceptance

- Inclusion in PubMed, CAS, Scopus and Google Scholar

- Research which is freely available for redistribution

Submit your manuscript at

www.biomedcentral.com/submit

() Biomed Central 